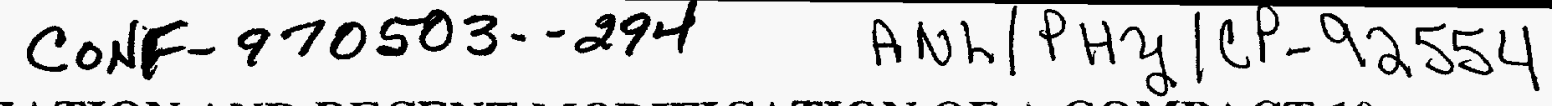

\title{
CHARACTERIZATION AND RECENT MODIFICATION OF A COMPACT 10 GHz ECRIS FOR ATOMIC PHYSICS EXPERIMENTS AND SPECTROSCOPIC INVESTIGATIONS
}

\author{
M. Schlapp 1 , R. Trassl ${ }^{2}$, R. W. McCullough ${ }^{3}$, J.B Greenwood ${ }^{3}$ and E. Salzborn ${ }^{2}$
}

RECEIVEO

JUL O 79997
OSTI

\section{Abstract}

A compact $10 \mathrm{ECR}$ ion source (200 mm long, 170 mm diameter) has been developed and tested. The complete magnetic structure made from permanent magnet material is comprised of four ring magnets producing an asymmetric axial magnetic field and a hexapole magnet with a maximum radial field of $0.94 \mathrm{~T}$ inside the plasma chamber. The coupling of the microwave to the plasma shows efficient ECR plasma heating at microwave power levels around 10 watts. Charge state distributions for various elements with intensities up to $320 \mathrm{e} \mu \mathrm{A}$ and their dependence on operation parameters will be presented as well as VUV spectra in the wavelength region down to 15 nm.

\section{INTRODUCTION}

There is a growing interest in the use of compact ECR ion sources with medium performances. In special environments, like small accelerators (Van-de-Graaff, Microtron), high voltage terminals or on line radioactive beam production systems with restricted space and low electrical power availability, this represents the only possibility to accelerate multiply charged ions. Recent advances in permanent magnet technology allow the design of compact all-permanent ECR ion sources operating at high frequencies. For use in an ion-ion experiment, employing the crossed beams technique [1] a first version of a compact $10 \mathrm{GHz}$ ECRIS was built [2]. A detailed description of the ion source is given elsewhere $[3,4]$. Furthermore the ionization and recombination processes occurring in an ECR plasma produce photons which are the basis for well established spectroscopic diagnostics [5]. These photons can be used for atomic structure studies and spectroscopic application, e.g. spectrometer wavelength scale calibration. Of special interest is the spectral range of the extreme ultraviolet
(EUV) below $20 \mathrm{~nm}$, where existing PIG sources produce spectral lines with low intensities and short operations times, due to the lifetime of their cathodes. ECR ion sources on the contrary show excellent long term stability and reproducibility because of only two operating parameters, gas pressure and microwave power [6].

\section{MODIFICATIONS}

\subsection{Source Description}

A cross section of the source is shown in Fig.1. Due to the poor extraction efficiency in previous runs a new insulation flange with a larger opening and a tapered puller electrode assembly has been built. All intensities shown below are obtained using this set up [7].

\subsection{Magnetic Field}

The axial magnetic confinement of the hot plasma electrons has been improved by using larger magnet rings

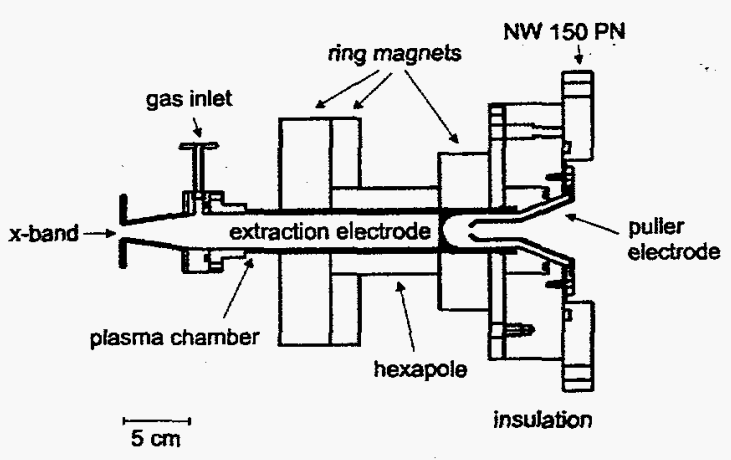

Fig. 1: Schematic view of the $10 \mathrm{GHz}$ ECRIS 


\section{DISCLAIMER}

This report was prepared as an account of work sponsored by an agency of the United States Government. Neither the United States Government nor any agency thereof, nor any of their employees, make any warranty, express or implied, or assumes any legal liability or responsibility for the accuracy, completeness, or usefulness of any information, apparatus, product, or process disclosed, or represents that its use would not infringe privately owned rights. Reference herein to any specific commercial product, process, or service by trade name, trademark, manufacturer, or otherwise does not necessarily constitute or imply its endorsement, recommendation, or favoring by the United States Government or any agency thereof. The views and opinions of authors expressed herein do not necessarily state or reflect those of the United States Government or any agency thereof. 


\section{DISCLAMIER}

Portions of this document may be illegible in electronic image products. Images are produced from the best available original document. 

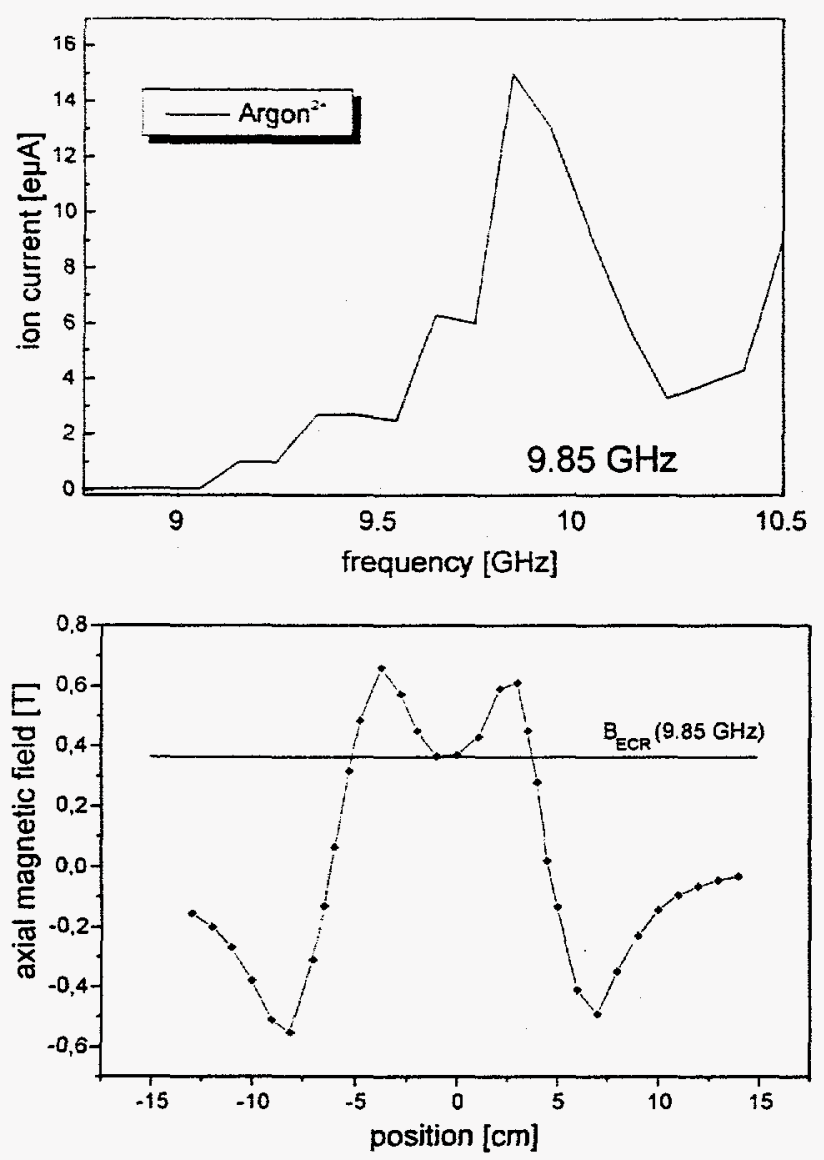

Fig. 2: Frequency dependence of the extracted $\mathrm{Ar}^{2+}$ beam intensity with cossesponding axial magnetic field

at the microwave injection side. The axial mirror ratio $B_{\max } / B_{\min }$ has been enhanced to 2.5 with a field maximum of $0.8 \mathrm{~T}$ and $0.5 \mathrm{~T}$, respectively. The Halbach-type 24segment hexapole magnet [8] (75mm long) gives a radial magnetic field of $0.94 \mathrm{~T}$ at the inner wall of the plasma chamber.

\subsection{Frequency Dependence}

The dependence of extracted intensities and charge states distributions on the applied microwave frequency has been investigated after installing the new magnetic system. The magnetron based microwave generator is tunable in the range of 8.75 to $10.5 \mathrm{GHz}$ with a maximum output power of 275 watts $\mathrm{c} / \mathrm{w}$. Fig. 2 shows the change in the extracted $\mathrm{Ar}^{2+}$ ion current at different microwave frequencies together with the axial magnetic field distribution for this experiment. It can be clearly seen that the best resuit is obtained when the frequency is set to a value where the minimum of the magnetic field is close to the resonance magnetic field strength. This result could be varified by using another permanent magnet configuration with a mirror ratios of 2.5 and 1.6, respectively. The best results were obtained at a frequency of $8.85 \mathrm{GHz}$, for which the resonance field was close to the minimum of the magnetic mirror.

\subsection{VUV Spectroscopy}

Measurements regarding the photon yield from an ECR plasma were performed by using a $32 \mathrm{~cm}$ grazing incidence spectrometer with a grating of $550 \mathrm{~g} / \mathrm{mm}$ with maximum efficiency at $15 \mathrm{~nm}$. The resolution of the spectrometer was $0.4 \mathrm{~nm}$ at a dispersion of $2 \mathrm{~nm} / \mathrm{mm}$ using an entrance slit of $100 \mu \mathrm{m}$. Fig. 3 shows a spectrum of a Neon plasma in the spectral range between 10 and $28 \mathrm{~nm}$, where mainly $\mathrm{Ne} \mathrm{IV}$ and $\mathrm{Ne} \mathrm{V}$ transitions could be identified. The stability of the plasma was measured by monitoring a single Ne II transition line, $2 \mathrm{~s}^{2} 2 \mathrm{p}^{5}-2 \mathrm{~s} 2 \mathrm{p}^{6}\left(^{2} \mathrm{P}\right.$ ${ }^{2} \mathrm{~S}$ ), at $44.7 \mathrm{~nm}$ over a period of 8 hours. Using this transition line we also found an excellent reproducibility after extinguishing and reigniting

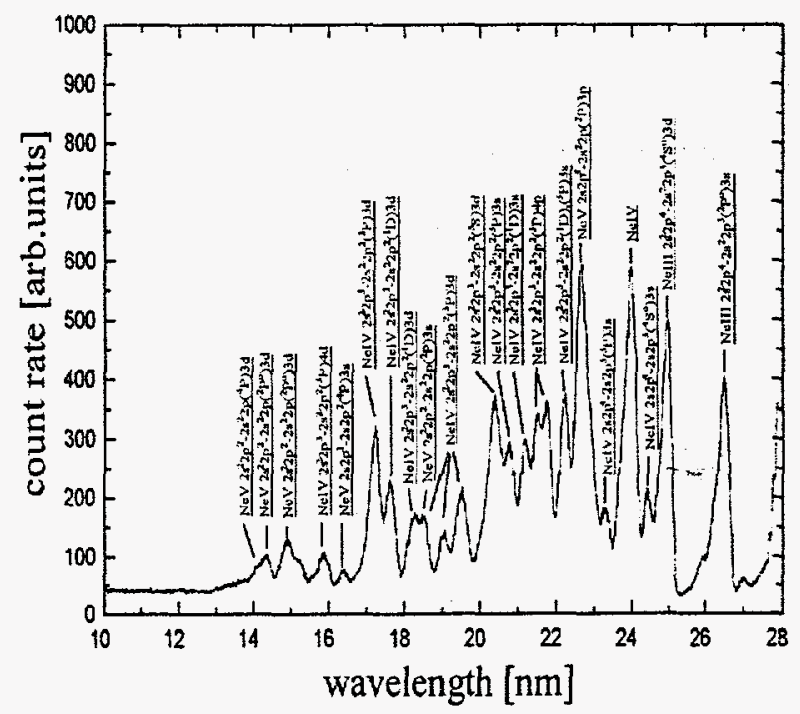

Fig. 3: Detailed line spectrum obtained from a Ne plasma using a $32 \mathrm{~cm}$ grazing incidence spectrometer 


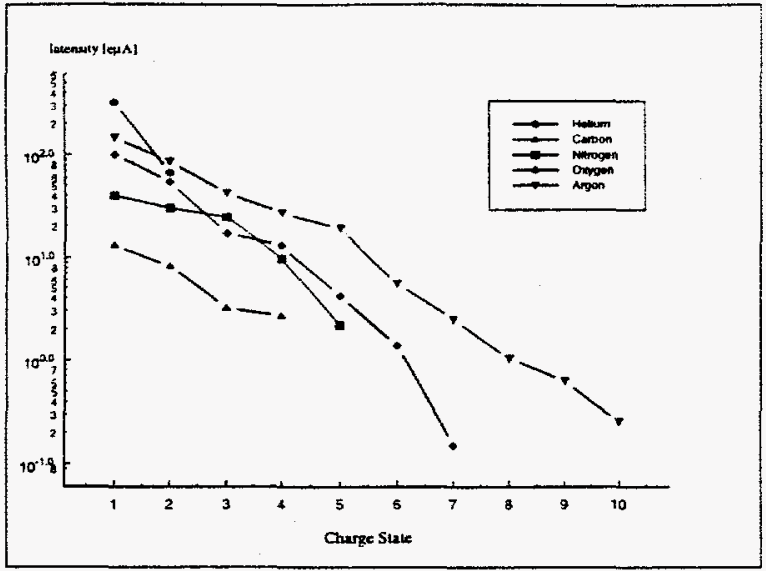

Fig. 4: Beam intensities for various gases at an extraction voltage of $9 \mathrm{kV}$.

the plasma by turning the microwave power off and on. Spectroscopy at higher resolution using a $5 \mathrm{~m}$ grazing incidence spectrometer has been performed recently and showed intense lines down to $12 \mathrm{~nm}$ obtained from a $\mathrm{Ne}$ plasma. No detailed results can be presented at this time.

\subsection{Beam Intensities}

The maximum beam intensities obtained from the compact ECR ion source are shown in Fig. 4. All beam currents were optimized on the respective charge state and measured in a Faraday cup after a $90^{\circ}$ analyzing magnet, at $9 \mathrm{kV}$ extraction voltage using a $5 \mathrm{~mm}$ diameter extraction aperture. Recent experiments using calibrated leaks of $\mathrm{Ne}$ and $\mathrm{CHF}_{3}$ for studies of the ionization efficiency have shown a poor transmission of the beam line used for these measurements. The ionization efficiency is an important factor in determining the usability for on line production systems in radioactive beam facilities.

\section{OUTLOOK}

Work is in progress to improve the residual gas pressure and the ion optical system which should result in higher charge states as well as in higher intensities. Recent measurements using calibrated leaks to determine the ionization efficiency have shown a preliminary value of approximately $30 \%$ for Neon. Identical measurements at both ECR ion sources at Argonne National Laboratory, a 2 stage $10 \mathrm{GHz}$ ECRIS and a newly constructed single stage $14 \mathrm{GHz}$ ECRIS [9] will allow to compare the effieciency of a compact source to high performance ECRIS.

\section{ACKNOWLEDGMENTS}

This work was supported by US D.O.E. Nuclear Physics Division under contract W-31-109-ENG-38. The authors gratefully acknowledge the support of the Queen's University in Belfast, the British Council and the German DAAD.

\section{REFERENCES}

[1] K. Rinn, F. Melchert, E. Salzborn., J. Phys. B. 19 (1986) 3717

[2] M. Schlapp, R. Trassl, E. Salzborn, R.W. McCullough, T.K. McLaughlin, H.B. Gilbody, Nucl. Instrum. Meth. B98 (1995) 525

[3] M.Schlapp, et al., 12th Intern. Workshop on ECR Ion Sources, RIKEN/Japan (1995) 71

[4] R. Trassl, P. Hathiramani, F. Broetz, J.B. Greenwood, R.W. McCullough, M. Schlapp, E. Salzborn, Physica Scripta (1997) (in print)

[5] W. Pöffel, K.H. Schartner, G. Mank, E. Salzborn, Rev. Sci. Instrum. 61 (1990) 613

[6] B. Lommel, K.H. Schartner, M. Schlapp, R. Trassl, E. Salzborn, 5th EPS Conf. on Atomic and Molecular Physics, Edingburgh/UK (1995) 601

[7] M. Schlapp, R. Trassl, R.W. McCullough, J.B. Greenwood, E. Salzborn, CAARI 96, Denton/Texas, USA (1996) (in print)

[8] K. Halbach, Nucl. Instrum. Meth., 169 (1980) 1

[9] M. Schlapp, R.C. Vondrasek, J. Szczech, P.J. Billquist, Z.Q. Xie, C.M. Luneis, R. Harkewicz, R.C. Pardo, 13th Intern. Workshop on ECRIS, College Station, Texas, USA, (1997) (in print) 